\title{
Study on the Synergy between Nuclear Power Industry and Regional Economic Development in China
}

\author{
Bing Liu, $\mathrm{Na} \mathrm{Yu}$ \\ University of South China, Hengyang, China \\ E-mail: BingLIU@usc.edu.cn,707176198@qq.com
}

\begin{abstract}
With the rapid economic and industrial development, China speeds up development of nuclear power (NP) to face the energy and the environment changes, and plans to increase in nuclear capacity to at least 58 GWe by 2020. Nowadays 16 provinces, regions and municipalities in China are petitioning for the establishment of NP plants. NP industry has played a vital role of developing regional economy around it. NP industry in the mechanism of interaction with the region's other subsystems can upgrade regional economic systems from a chaotic state to an orderly or systematical one. Because NP industry can promote the regional overall economic strength and it has generated essential changes of the supply capacity of funding, the level of financial and self-development capability in the region. NP industry also can improve the region's overall economic conditions. It is not only to improve the deteriorating environment, but also to promote infrastructure construction and social undertakings. And NP industry affects the regional overall technological strength. NP industry is a high-tech industry that plays a strategic function in region's industries. It helps promote technological improvements, brings technological changes and innovations on rules, leads the development of human resources, and enhances the ability of an export-oriented economy. Finally NP industry in the region can optimize industrial restructuring. It can form the gathering of human resources, capital and information flows, effects the formation of the leading industry and promotes the development of some traditional industries.
\end{abstract}

Keywords-synergistic; NP Industry; regional economic development

\section{INTRODUCTION}

Owing to the rapid development of nuclear technology, the rising natural gas and coal prices and the reality of serious environmental pollution and global warming in the beginning of 21st century, many countries establish their long-term energy strategy including expanded the development of NP industry. NP accounting for $11 \%$ of global generating capacity at the end of 2015 becomes the world's third largest pillar of power, and more than $90 \%$ of the installed capacity of
NP is mainly distributed in OECD countries. United States, Japan, Britain, France, and other developed countries all have a ratio of more than $25 \%$ of the national energy output.

According to IAEA statistics in January 2016, a total of $440 \mathrm{NP}$ plants are in operation around the world, with a combined capacity of 2,411 billion $\mathrm{kWh}, 65$ reactors are under construction with the installed capacity of $68,935 \mathrm{MWe}$. And 73 reactors with total installed capacity of $182,424 \mathrm{MWe}$ are planned; 337 reactors are on the proposed plan. With the increase concentrated heavily in China (46\% of it), plus India, Korea and Russia (30\% of it together) and the USA (16\%), countered by a $10 \%$ drop in the EU.

\section{NP INDUSTRY'S ROLE IN CHINA'S ECONOMIC DEVELOPMENT}

Ever since the 1970s China has gained great development in the NP construction. Qinshan NP Plant,China's first self-designed, started operation on December 15, 1991 .The industry moved into a rapid development phase, in the 11th five-year plan, China generated 47.8TWh of nuclear power, which accounted for around $2.2 \%$ of the total electricity generation of the country (As showed in table I ), and nine units had been put into commercial operation in the mainland of China. The "medium-and long-term NP development plan (2005-2020)" claims that China plans to generate 20 million kilowatts of installed capacity before the year of 2010 and 40 million kilowatts which represents 4 percent of China's total output of electric energy by 2020. China's per capita energy consumption will reach 1 kilowatt of electricity capacity by then, with the 1.5 billion populations, there should be 15 million kilowatts. As shown in table2, by the end of the 12th Five Year Plan some $25 \mathrm{GWe}$ of new capacity was planned to be operational, making some $40 \mathrm{GWe}$ and $45 \mathrm{GWe}$ more might be added by the end of the 13th Five Year Plan. It means that China should build 220 Block 100-kilowatt NP stations that have to say, a year from now average four 100-kilowatt NP stations should be completed in order to achieve this objective. 
TABLE I. OPERATING NUCLEAR REACTORS IN MAINLAND OF CHINA ${ }^{[1]}$

\begin{tabular}{|c|c|c|c|c|c|}
\hline Units & Province & $\begin{array}{c}\text { Net capacity } \\
\text { (each) }\end{array}$ & Type & Operator & Commercial operation \\
\hline Daya Bay $1 \& 2$ & Guangdon & $944 \mathrm{MWe}$ & French M310 & CGN & 1994 \\
\hline Oinshan Phase I & $\underset{\text { Zheiiang }}{\mathrm{g}}$ & $298 \mathrm{MWe}$ & CNP-300 & $\mathrm{CNNC}$ & April 1994 \\
\hline Qinshan Phase II, 1\&2 & Zhejiang & $610 \mathrm{MWe}$ & CNP-600 & CNNC & 2002,2004 \\
\hline Qinshan Phase II, 3\&4 & Zhejiang & $619,610 \mathrm{MWe}$ & CNP-600 & $\mathrm{CNNC}$ & 2010,2012 \\
\hline Qinshan Phase III, 1\&2 & Zhejiang & $677 \mathrm{MWe}$ & Candu 6 PHWR & $\mathrm{CNNC}$ & 2002,2003 \\
\hline Fangjiashan 1\&2 & Zhejiang & 1020 MWe* & CPR-1000 (M310+) & $\mathrm{CNNC}$ & Dec 2014, Feb 2015 \\
\hline Ling Ao Phase I, 1\&2 & Guangdon & $950 \mathrm{MWe}$ & French M310 & CGN & 2002, 2003 \\
\hline $\begin{array}{l}\text { Ling Dong/Ling Ao Phase II, } \\
1 \& 2\end{array}$ & $\begin{array}{c}\mathrm{g} \\
\text { Guangdon } \\
\mathrm{g}\end{array}$ & $1007 \mathrm{MWe}$ & CPR-1000 (M310) & CGN & Sept 2010, Aug 2011 \\
\hline Tianwan 1\&2 & Jiangsu & $990 \mathrm{MWe}$ & VVER-1000 & $\mathrm{CNNC}$ & 2007,2007 \\
\hline Ningde $1 \& 2$ & Fujian & $1018 \mathrm{MWe}$ & CPR-1000 & CGN \& Datang & April 2013, May 2014 \\
\hline Ningde 3\&4 & Fujian & $1018 \mathrm{MWe}$ & CPR-1000 & CGN \& Datang & June 2015, (June 2016) \\
\hline Hongyanhe $1 \& 2$ & Liaoning & $1061 \mathrm{MWe}$ & CPR-1000 & CGN \& SPI & June 2013, May 2014 \\
\hline Hongyanhe $3 \& 4$ & Liaoning & $1060 \mathrm{MWe} *$ & CPR-1000 & CGN \& SPI & Aug 2015, (early 2017) \\
\hline Yangjiang 1\&2 & Guangdon & $1020 \mathrm{MWe} *$ & CPR-1000 & CGN & March 2014, June 2015 \\
\hline Yangjiang 3 & $\begin{array}{c}\mathrm{g} \\
\text { Guangdon } \\
\mathrm{g}\end{array}$ & $1020 \mathrm{MWe}^{*}$ & CPR-1000+ & CGN & Jan 2016 \\
\hline Fuqing 1\&2 & Fujian & $1020 \mathrm{MWe}^{*}$ & CPR-1000 (M310+) & CNNC \& Huadian & Nov 2014, Oct 2015 \\
\hline Fangchenggang 1 & Guanxi & $1020 \mathrm{MWe} *$ & CPR-1000 & CGN & Jan 2016 \\
\hline Changjiang 1 & Hainan & $610 \mathrm{MWe}$ & CNP-600 & $\begin{array}{l}\text { CNNC \& } \\
\text { Huaneng }\end{array}$ & Dec 2015 \\
\hline Total: 32 & & 28,967 MWe & & & \\
\hline
\end{tabular}

* Estimate based on 1080, 1086 or 1089 MWe gross, except Hongyanhe 3 \& 4: 1119 gross; other net figures from PRIS.

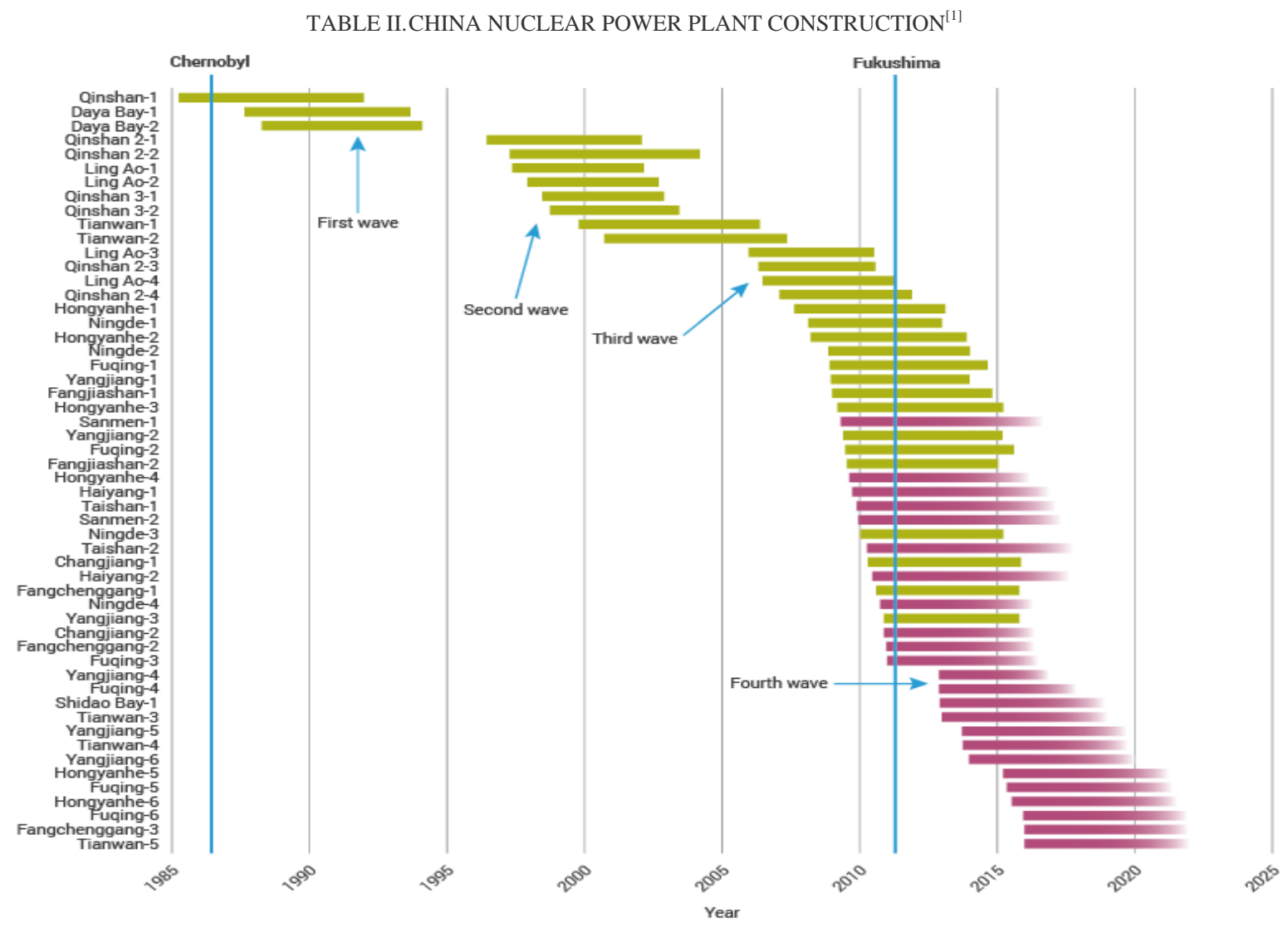




\section{SYNERGISM AND SYNERGISTIC EFFECT}

Haken, a German, presented synergetic to study self-organization rule on how systems had evolved from disorder to order in 1973. The focus of synergetic is the qualitative changes of complex system's macroscopical character. The system's initial conditions can be seems as the superposition of all the possible state, one of them or one special aspect 's structure dominate the others, and then it is strengthen gradually while other state or aspect is restrained .Finally, every state of the system is pulled to this special orderly state. [2][3]

Synergistic effect refers to in the complex big system, every sub-system's synergism interaction generate effect beyond its own separate effect in a large, thus forming a unity and joint role of all the system. Synergistic effect emphasizes that combination's effect more than the sum of its parts. The combination's effect contains the following two aspects: (1) the combination of different units causes some unit's resource which has not been fully utilized will be more fully utilized. In other words, the whole efficiency is enhanced by enlarging the use range of resource. Actually, in this mode which named static synergism every unit resource's - 3 efficiency is not enhanced. (2) the compounding of different units leads to the full share of knowledge and skill and then enhances the whole efficiency. That is to say, the individual's ability to create value is enhanced by improving the efficiency of overall resources se, and the whole effect therefore is elevated. In this mode which named dynamic synergism, the unit resource's efficiency is enhanced. [4]

\section{THE SYNERGY BETWEEN NP INDUSTRY AND REGIONAL ECONOMIC DEVELOPMENT}

H. Igor Ansoff (1965), a well-known strategy scholar in U.S., published the "corporate strategy" putting forward that by the merger and reorganization enterprises can realize diversification to create Synergies. The theory of such interior synergy, however, had been challenged by the theory of strategic business unit in 1980s. Michael Porter coordinated the theory of synergy and strategic business unit to explore how can an enterprise create and maintain profitability within one or more industries [5]. And the evolution from interior synergy to exterior synergy created a synergy between industry and regional economic development. Here regional economic development is defined as the optimization and elevation of the economic and social structure on the basis of the growth in economic outputs; it mainly focuses on improving the quality of economic development. [6] A synergy between NP industry and regional economic development means that NP industry in the mechanism of interaction with the region's other subsystems can upgrade regional economic systems which contain the structures of the space, time, and function distributions from a chaotic state to an orderly or systematical one, and the synergy between them is the cause of the function and evolution of emergent qualities such as qualities of the capital supply, financial resources, transportation environment, natural environment, etc. it also reveals the overall mechanism of evolution, and predicts future changes. [7]

\section{A. NP industries and the Teem of the region's economic growth}

There always exist various factors constraining the growth in economic strength In the process of regional economic growth, and these that are most vulnerable to changes and have a decisive impact on the economic growth are called the order parameters in Synergetic. [8] Enterprises in the nuclear industry are generally in the underdeveloped areas, so huge investment and the related ancillary facilities are the dominant indicators of regional economic strength. To construct a 100-kilowatt NP plant costs more than 1 billion U.S. dollars in a region, the huge strategic capital thus becomes the most influential factor in that region, and causes dramatic, qualitative changes in the ability of capital supply, the level of financial resources and the self-development ability .For example, Haiyan County of zhejiang Province since its construction of the Qinshan NP Station at the beginning of the 1980s, had its GDP increased from 310 million yuan to 110.8 million yuan, and an nearly 35.6-fold increase. And local fiscal revenue increased to 347 million yuan from 35.19 million yuan, an increase of nearly 10 times. In 2004, GDP in Haiyan County was about 14.05 billion Yuan in 2004, about 4,460 U.S. - 4 - dollars GDP per capita. NP system contributed 4.75 billion yuan, accounting for $33.8 \%$ of GDP in the county. Daya Bay NP plant in Guangdong Province with total investment of 4 billion U.S. dollars had started with zero capital, depended on loans, and sold electric power to pay off. Guangdong NP Investment Co. td., And Hong Kong NP Investment Co. Ltd., Jointly established Guangdong NP Joint Venture Company with the former 300 million U.S. dollars while the latter 100 million U.S. dollars to invest, construct and manage Guangdong Daya Bay NP plant, the remaining 3.6 billion U.S. dollars was raised from international capital market under the Chinese bank guarantee, and paid off the loans by selling electricity. From the beginning to 2002, Daya Bay NP Station had realized profits and taxes of several hundred million yuan, and all taxes paid more than 200 million yuan. Today there are nearly 60 billion yuan in assets and the policy of " supporting nuclear with nuclear " led to the establishment of the Ling Ao NP Station and the development of relevant industries.

\section{B. NP industry and the evolvement of the region's overall environmental conditioning}

As shown in figure 1, NP is clean and reliable energy, it produces no air pollution or greenhouse gases such as carbon dioxide, and there is a growing consensus that it is an environmentally responsible choice. According to statistics, China's annual economic losses caused by air pollution and acid rain reached 37 billion U.S. dollars, around 5\% of GDP. From the perspective of the evolution of transportation, a 100-kilowatt coal-fired power plant needs 2.6 million tons of coal annually. In other words, its need to ship 10,000 tons of coal or drive five trains with capacity of 1,400 tons to 
transport coal in a day. However, a 100-kilowatt pressurized water reactor NP plant only needs transportation about a million tons of nuclear fuel assemblies. [9] The NP industry promotes the evolution of the environment conditioning mainly by improving infrastructure. Nuclear industry as a complex product requires relatively high matching facilities, which will promote the development of urban construction and social undertakings. For example, these living facilities such as "Nuclear Village", "Nuclear South Garden", and "Canadian Expert Village" in the Qinshan NP Plant are becoming bright spots in the urban construction, and had been rated as civilized living quarters by Jiaxing City government and Zhejiang Province government. And it was exactly because of the Qinshan NP Station that the north pier of the Hangzhou Bay Bridge a 3.6-km cross-sea bridge was designed to be located in Haiyan Country territory. In addition, some supporting the construction of NP are playing the corresponding efficiency as "Ocean Terminal" and the fairways opened up a new sea route for Haiyan people so that the first commercial sea "LNG terminal" was built and put into use; the "Qinshan Road" emergency project was built by the NP plant and the local government, to some extent, has eased the congestion situation in Qinshan region, and led to the construction of the villages and towns along the highway. All these - 5 - examples are embodied in the high level of synergy between the NP industry and the construction of regional infrastructure.

\section{The NP industry has a significant impact on the function of science and technology in a region}

The NP industry is a strategic industry of high technology, and the NP plant is a high-tech integrated project, so it has trained a large number of research, construction, debugging and management talents in the process of research design, construction and installation, project supervision, procurement of equipment manufacturing, the production of nuclear fuel assemblies, and construction, commissioning, operation. Currently, nuclear technology has been widely used in agriculture, medicine and many other fields, to the end of the 20th century, the application of nuclear technology had created a billion level output value each year in the world. The economic output of nuclear technology industries each year in Europe and the United States has represented 2\%-5\% of GDP, the ratio of its input to output was 1:5 to $1: 10$, and it has created nearly four million new jobs.

China's nuclear industry as an emerging one brings about technological change and innovation, promotes human resources cooperation, and has become one of the sources of innovation. In 2003, the application of nuclear technology in China created a direct economic benefit of approximately 376 billion Yuan per year, around $0.3 \%$ of its GDP. In 2004, the State Development and Reform Commission issued "a special notice on the organization and implementation the high-tech industrialization of non-power nuclear technology for civilian use" to speed up the pace of the development of NP and industrialization of nuclear fuel. And by 2020, China's nuclear industry will be developed into a special industry with comparative advantages. NP industry is a high-tech intensive industry involved in the development of nuclear materials, metallurgy, chemical industry, machinery, electronics, equipment manufacturing and other sectors, and due to the special nature of it, the technology requirements of these industries are of very high standards, the development of NP technology is conducive to promoting the improvement of their technology and raising the level of technology and management standards. The constriction costs of a 1-million-kilowatt twin reactor station are expected to be 1,500 U.S. dollars / $\mathrm{kWh}$, that is to say, the costs amount to three billion U.S. dollars and approximately 25 billion Yuan. The independent construction and localization of NP plant help provide a greater market for our equipment manufacturing industry and promote the development of the entire national economy. NP industry in its special status has a close relationship with various central ministries, research institutes in China and has frequent exchanges with many developed countries such as the United States, France, Germany, Japan, Canada, South Korea and etc. It has become the key forces to cultivate the overall function of the technology market and the applications of scientific and technological achievements.

\section{NP industry and regional industrial restructuring}

Taking a new road to industrialization and direct investment in regional development strategy are two important motivating factors affecting the regional economy, and regional economic development is bound to stimulate greater investment and industrial restructuring to rationalize the structure of the region.

Rationalization of the structure of the region, based on regional resources, scientific and technological level of economic development, international trade relations and the quality of the population and etc, realize the rational allocation of production factors, it is a coordinated development between industries.[10] To achieve Rationalization of the structure of the region, the choice of key industries is of vital importance, and the development of the NP industry have an important impact on the selection of regional dominant industries. China has clearly put forward that in order to accelerate the development of NP industry, first of all, the role of high-tech factors in the NP industry should be fully played, and then the regional economic system should be elevated from a state of chaos to an orderly one in terms of space, time, and function structure in the mechanism of interaction between NP industry and the subsystems of human resources, self-development, and structural adjustment. In the exploitation of the international transfer of nuclear technology and external factors, China must maintain control and support the development of these industries which of essential to enhance the comprehensive national strength, and short-term interest will not be to make the industrial group, China needs developing strategic industries. To bring the radiation function of the strategic industries can form the gathering of human resources, capital and information flows. And through technological transformation of the region's 
related industries, advancement and extension of the industrial chain, increase in the added value, and development of the enterprise groups with core competencies, the leading industries will follow (Shown in Figure1).

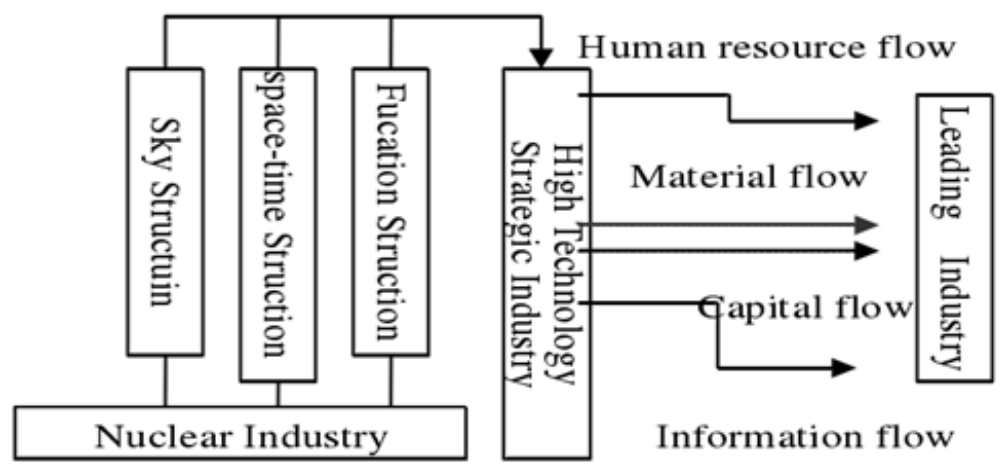

Figure.1. Nuclear-Leading Industry switch Mechanism

\section{CONCLUSION}

China's traditional "pollution first, later, the first scale, after the effectiveness" of regional economy and management mode could no longer meet the needs of China's economic development. "PRC 10th Five-Year Plan for National Economic and Social Development Program," pointed out the necessity to change the mode of economic growth, optimization and upgrading of industrial structure and promotion industry from large to strong should depend on raising the overall technological level. This paper analyzes the socio-economic system by synergy theory, and changes the way of decision-making from the linear thinking to the systematic thinking. It proposes that there exists a synergy between NP Industry and regional economy, environment, science and technology, and nurturing nuclear industry should promote regional economic coordination and sustainable development.

\section{REFERENCES}

[1] $[\mathrm{EB} / \mathrm{OL}]$. http://www.world-nuclear.org/information-library/country-profiles/co untries-a-f/china-nuclear-power.aspx, 201654.4.

[2] Haken.H, "Advanced Synergetics", Berlin: Spinger-verlag, 1983, P56-60.

[3] Wang Guiyou, "Order - the summarize of synergistic", Hubei hall Press, 1987.

[4] M. E. Poter, "Competitive Advantage", New York: The Free Press, 1985.

[5] Poter, M. Z, "Competition in Global Industries", Harvard Business Press, 1986.

[6] Joseph.E.Stiglitz , Car 1.E.warsh. Economics, 3rd, ed, Prentice Hall, Sep., 2000.

[7] LIU Bing, WANG Xin, FEI He-fu, "Technology Capacity Evolution and Technology Catch-up in China Nuclear Power", pp. 1-4, Feb., 2013.

[8] Hanken H, Synergetics, an introduction. 3rd ed, Berlin Heidelberg: Springer Ser syn, 1987.

[9] Zeng Shaolun, "On China's Sustainable Development of Energy Opportunity for the Chian's NP Industry", Ecological economy, pp 12-17, Feb. 2005.

[10] Huang Jizhong, The lopsided increase theory in District economics, Bei Jing: Economic and Management Press, 2001. 